\title{
FINITE ELEMENT ANALYSIS OF AN IMPLANT GENESIS AKTIV MODEL IN THE DETERMINATION OF INSERTION TORQUE AND OCCLUSAL FORCE
} \author{
KODE JAYA PRAKASH ${ }^{1}$, Dr. BALLA SRINIVASA PRASAD ${ }^{2} \&$ Dr. ARVIND UD ${ }^{\mathbf{3}}$ \\ ${ }^{1}$ Research Scholar, Department of Mechanical Engineering, GIT, GITAM (Deemed to be University), \\ Visakhapatnam, Andhra Pradesh, India \\ ${ }^{2}$ Associate Professor, Department of Mechanical Engineering, GIT, GITAM (Deemed to be University), \\ Visakhapatnam, Andhra Pradesh, India \\ ${ }^{3}$ Oral and Maxillofacial Surgeon, Dr.Arvind's Dental and Maxillofacial Clinic, Hyderabad, Telangana, India
}

The finite element analysis (FEA) has been used extensively to predict the biomechanical performance of various dental implant designs as well as the effect of clinical factors on implant success. It is an ultimate method for modelling complex structures and analyzing their mechanical properties. In Implantology, FEA has been used to study the stress patterns in various implant components and also in the peri-implant bone. It is also useful for studying the biomechanical properties of implants as well as for predicting the success of implants in clinical condition. The Human Mandible of a male patient aged 53 years, which is having first molar missing, is chosen to carry out the FEA Analysis. The Von-Mises Stress, Total deformation is solved for both insertion torque and occlusal force. The FEA analysis is carried out on the first molar contact condition as per the literature available based on the very moment of occlusion to maximum biting. Similarly, the implant insertion torque values are taken from the literature and also from the Implant Genesis insertion torque value standards. In this present work, the Implant Genesis Aktiv Model dental implants of different diameters, lengths along with its structure is being modelled and the suitable implant required for the selected patient is identified from the NNT Viewer software by New Tom which is widely used by Dental surgeons in implantology and maxillofacial surgeries for study of the CBCT (Cone Beam Computerized Tomography) scans in multiple views and planning of the surgeries. The Implant Genesis Aktiv Model implants are made of Titanium Grade 4 (Ti-6Al-4V) and the same is given as material properties for performing FEA Analysis. The results attained from the insertion torque and Occlusal force shows that the formation of Von Mises stresses are very low, and the all the stress values generated are permissible for the mandible.

KEYWORDS: Dental Implant, Mandible STEP File (Standard for the Exchange of Product Model Data), CATIA V5 \& Finite Element Analysis
\end{abstract}

Received: Apr 22, 2020; Accepted: May 13, 2020; Published: Jun 08, 2020; Paper Id.: IJMPERDJUN202089

\section{INTRODUCTION TO FINITE ELEMENT ANALYSIS IN DENTISTRY}

The finite element analysis (FEA) is an upcoming and significant research tool for biomechanical analyses in biological research. It is an ultimate method for modelling complex structures and analyzing their mechanical properties. FEA has now become widely accepted as a non-invasive and excellent tool for studying the biomechanics and the influence of mechanical forces on the biological systems. It enables the visualization of superimposed structures, and the stipulation of the material properties of anatomic craniofacial structures [1]. It also allows establishing the location, magnitude, and direction of an applied force, as it may also assign stress points that 
can be theoretically measured. Further, as it does not affect the physical properties of the analyzed materials it is easily repeatable $[2,3]$.

In the human body, there are individual variations with respect to bone quality, quantity and shape which have an important impact on the prognosis of the implant or regenerative treatment. Recently with the advances of digital imaging systems (CT and MRI), it has become possible to extrapolate the individual specific data of bone geometry and property to an FEA model. These patient specific "biological data based FEA" are peculiar to that patient as bone morphology and quality vary among individuals. Thus, very accurate anatomical models can be created which in turn provide reliable results $[4,5]$.

In FEA studies to assess mechanical stress in the peri-implant bone, stresses of various kinds which are used include von Mises stress, the maximum, the minimum principal stress and the maximum shear stress. The von Mises stress is the most frequently and mainly used scalar-valued stress invariant to appraise yielding/failure behaviour of various materials[6].

The success of FE modelling depends on the accuracy in simulating the geometry and surface structure of the implant, the material characteristics of the implant and jawbone, the loading and support conditions as well as the biomechanical implant-jawbone interface. FEA gives an in depth idea about the stress patterns in the implant. This knowledge about the stress patterns and distribution will lead to improvement in implant designs and placement techniques. FEA has been extensively used to predict the biomechanical performance of various dental implant designs, as well as the effect of clinical factors on the success of implantation.

If the occlusal forces around a dental implant are distributed homogenously then the bone is maintained well. When we look into the literature several attempts to preserve the marginal bone around dental implants has been done [7]. Contributing factors for marginal bone loss that have been accepted to some degree are biological, clinical and mechanical factors [8]. It is vital to understand the biomechanical behaviour of bony tissues and dental implants in order to prevent marginal bone loss and implant failure.

In order to prevent implant failures and complications due to mechanical and technical factors, these factors have to be evaluated in advance. As a result use of these essential steps could increase the survival rate of implant-supported restorations. Hence, there has been a dramatic increase in the number of biomechanical studies in the field of implant dentistry in an effort to decrease dental implant failure rates [9].

\section{MODELLING OF IMPLANT GENESIS AKTIV MODEL DENTAL IMPLANTS}

The dimensions of implants are very small ranging from $0.1 \mathrm{~mm}$ to $13 \mathrm{~mm}$. The Implant Genesis AKTIV models are having tapered shape and made of buttress thread. The same is chosen for modelling using CATIA V5 Modelling software. Advantages of Butress thread of the AKTIV model ensures the Easy and smooth insertion, Fast and controlled bone penetration, Excellent bone grip, Moderate self-drilling capability. Implants having diameters 5 mm (Figure 1) and $4.2 \mathrm{~mm}$ (Figure 2) with each diameter having varying lengths between $8 \mathrm{~mm}$ to $13 \mathrm{~mm}$. Table 1 shows the Implant type, Implant diameter and Lengths were obtained from Implant genesis implants. 
Table 1: Implant Genesis Diameter and Lengths

\begin{tabular}{|c|c|c|c|}
\hline SI. No. & Implant Type & Implant Diameter & Implant Lengths \\
\hline 1. & Tapered- Buttress thread & $4.2 \mathrm{~mm}$ & $8 \mathrm{~mm}, 10 \mathrm{~mm}, 11.5 \mathrm{~mm}, 13 \mathrm{~mm}$ \\
\hline 2. & Tapered- Buttress thread & $5 \mathrm{~mm}$ & $8 \mathrm{~mm}, 10 \mathrm{~mm}, 11.5 \mathrm{~mm}, 13 \mathrm{~mm}$ \\
\hline
\end{tabular}

The dimensions required for modelling are obtained. Now a 3D model of the implant has been prepared using CATIA.

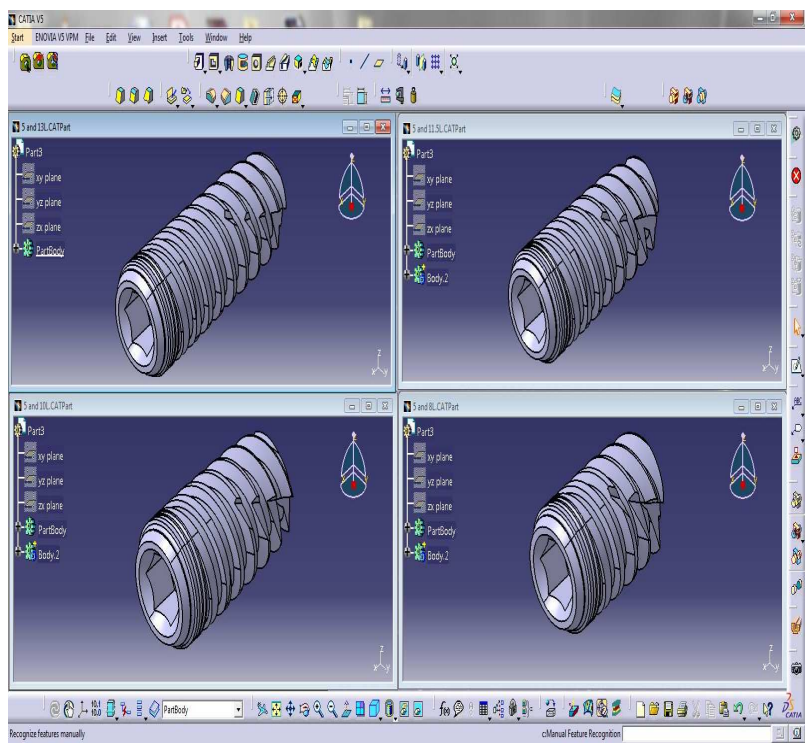

Figure 1: Implant Genesis Aktiv Implants of Dia 5mm and $13 \mathrm{~mm}, 11.5 \mathrm{~mm}, 10 \mathrm{~mm}, 8 \mathrm{~mm}$ Lengths.

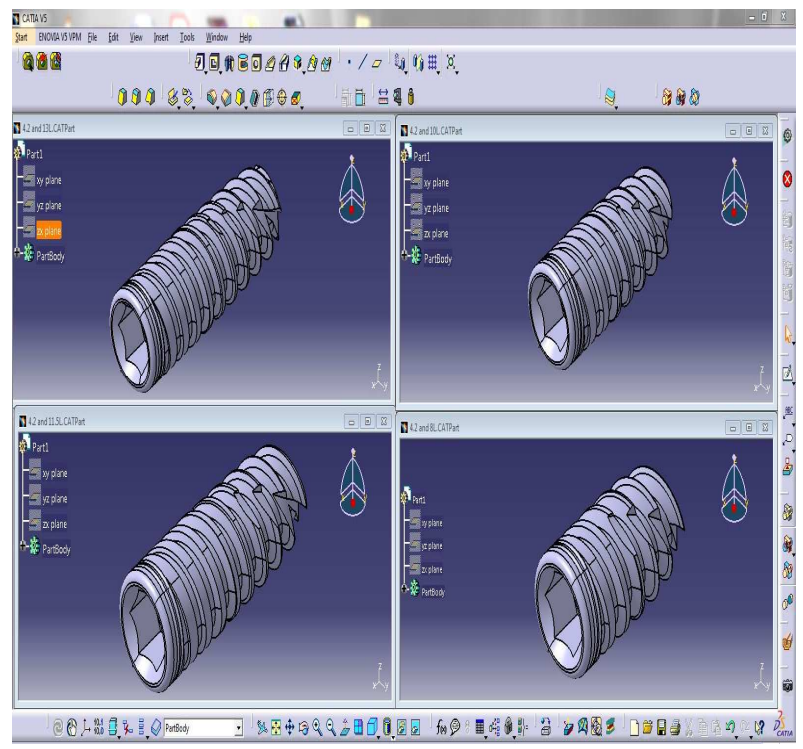

Figure 2: Implant Genesis Aktiv Implants of Dia

$4.2 \mathrm{~mm}$ and $13 \mathrm{~mm}, 10 \mathrm{~mm}, 11.5 \mathrm{~mm}, 8 \mathrm{~mm}$ Lengths.

\section{SELECTION OF DENTAL IMPLANT AND ITS POSITION}

The patient specific implant model, Diameter, length, implant position and depth to be implanted is identified from the NNT Viewer software by New Tom which is widely used in impalntology and maxillofacial surgeries to see the multiple 
views of the CBCT Scans and for planning of the dental surgeries. The (Figure.3) shows the implant position, diameter and the length to be inserted inside the mandible and (Figure.4 and Figure.5) shows the exploded view and the Assembly of the implant. The implant diameter of $5 \mathrm{~mm}$ and length $11.5 \mathrm{~mm}$ is selected for implantation as shown below in the picture of the NNT Viewer.

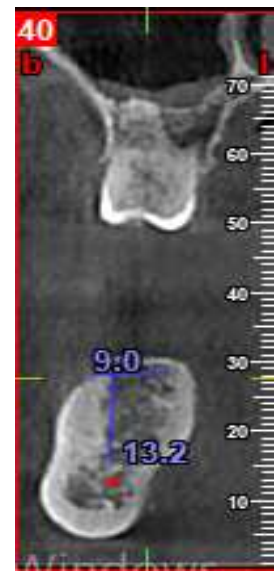

Figure 3: Implant Position and length seen in NNT Viewer.

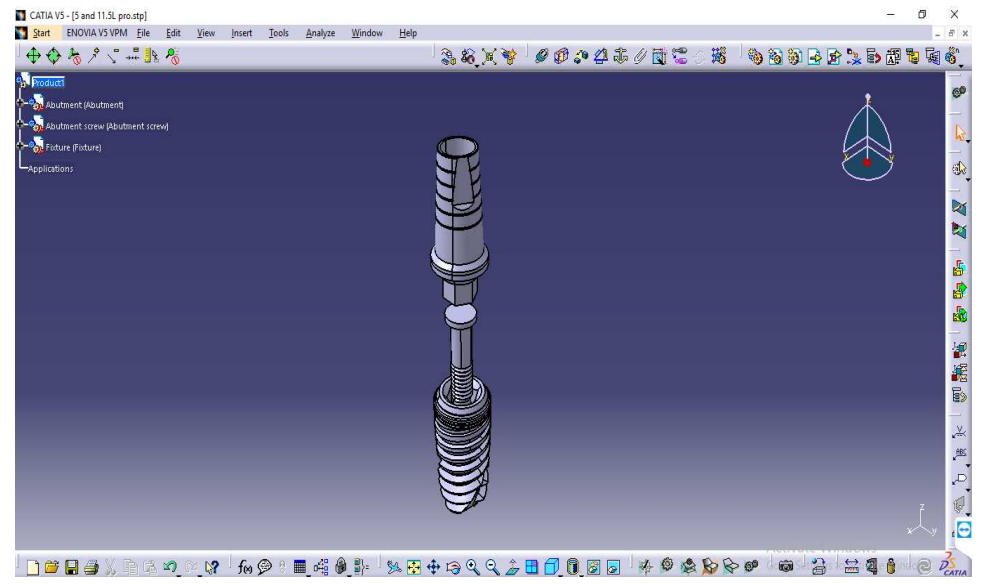

Figure 4: Exploded view of Implant Genesis Aktiv Implant of Dia 5mm and $11.5 \mathrm{~mm}$ Length with Abutment, Screw and Fixture.

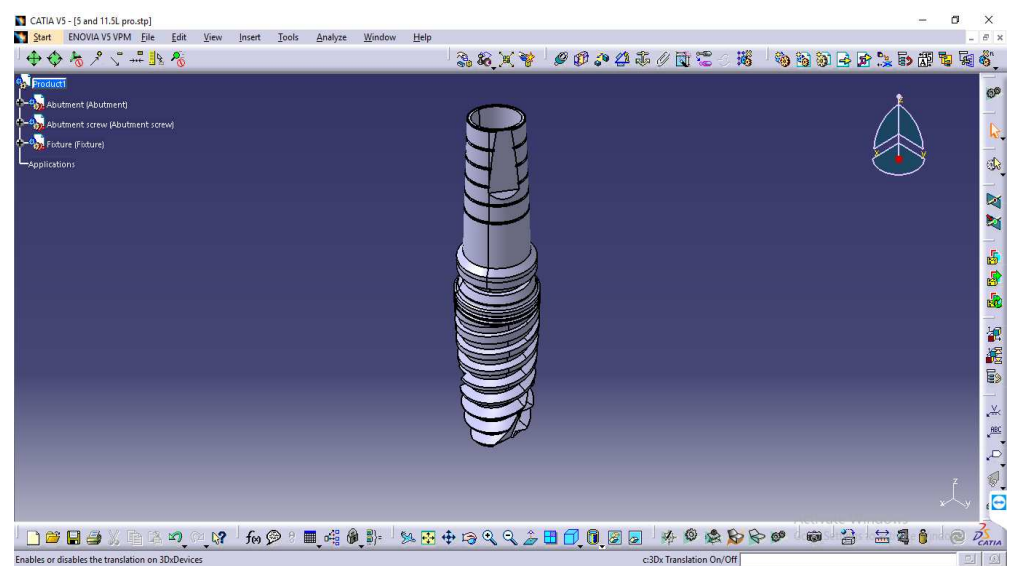

Figure 5: Assembly view of the Implant Genesis Aktiv Implant of Dia $5 \mathrm{~mm}$ and $11.5 \mathrm{~mm}$ Length. 


\section{PREPARING AND CONVERSION OF STL FILE TO STEP FILE FOR PERFORMING FEA ANALYSIS}

The CBCT DICOM (Digital Imaging and Communications in Medicine) file of the patient is taken and processed into STL Rapid Prototyping File (Standard Tessellation Language) using Invesalius Medical Modelling software. The STL file attained from the medical modelling software is processed in Meshmixer and Altair Hypermesh softwares for the rectification of geometrical errors and for giving bone densities of Cortical and Cancellous bones, and further converted into STEP (Standard for the exchange of Product model data) File format for performing the analysis in the ANSYS Software. The reason for using the hypermesh is to retain the accuracy of the file. The Cortical and cancellous bone thickness is taken from NNT Viewer software by New Tom, and the same is implemented on the STEP File to perform analysis.

According to the literature, occlusal force is mostly generated in the molar tooth; hence the first molar missing teeth human mandible is chosen to perform FEA Analysis. Figure 6 shows the Cross-sectional model of the STEP file utilized to build the assembled model of the implant system, showing cortical and cancellous bones done in Altair Hypermesh (13.0) and nerve model is drawn using using CATIA V5 Software, Dassault Systems. The nerve model is constructed below the apex of the fixture and a standard gap of 1-2mm should be maintained by every maxillofacial surgeon while doing the implantation, and care should be taken that the fixture should not touch or press the nerve as it leads to the total numbness of the entire jaw. The thickness of the cortical bone is to be taken as $1 \mathrm{~mm}$ as shown in (Figure.7 white boundary) upper right side of NNT Viewer. The Cortical bone thickness will vary from person to person, age to age which can be clearly seen in NNT Viewer. Table 2 shows the Material Properties applied on the STEP File for FEA Analysis [11]. A mesh on the STEP file was formed using ANSYS software (15 Version). The information of the mesh size, type of mesh, contact elements, total number of nodes and elements is shown in the below table 3 .

Table 2: Material Properties Applied on the

STEP File of the Mandible for Analysis

\begin{tabular}{|l|c|}
\hline \multicolumn{1}{|c|}{ Components } & $\begin{array}{c}\text { Nodes, elements } \\
\text { \& Mesh Size (mm) }\end{array}$ \\
\hline Abutment & 0.15 \\
\hline Fixture & 0.15 \\
\hline Abutment Screw & 0.15 \\
\hline Cortical Bone & 1.0 \\
\hline Cancellous Bone & 1.0 \\
\hline Number of Total Nodes & 1120024 \\
\hline Number of Contact elements & 156252 \\
\hline Number of Solid elements & 754661 \\
\hline Number of Total elements & 910913 \\
\hline Type of Mesh & $\begin{array}{c}\text { Tetra Four node } \\
\text { configuration }\end{array}$ \\
\hline
\end{tabular}

Table 3: Mesh Size, Nodes and Elements Data of the Patient's STEP File of the Mandible

\begin{tabular}{|l|c|c|}
\hline Components & $\begin{array}{c}\text { Young's } \\
\text { Modulus } \\
\text { (Mpa) }\end{array}$ & $\begin{array}{c}\text { Poisson's } \\
\text { Ratio }\end{array}$ \\
\hline $\begin{array}{l}\text { Abutment } \\
\text { (Ti grade 5) }\end{array}$ & 114,000 & 0.33 \\
\hline $\begin{array}{l}\text { Fixture } \\
\text { (Ti grade 4) }\end{array}$ & 105,000 & 0.34 \\
\hline
\end{tabular}




\begin{tabular}{|l|c|c|}
\hline $\begin{array}{l}\text { Abutment Screw } \\
\text { (Ti grade5) }\end{array}$ & 114,000 & 0.33 \\
\hline Cortical Bone & 13,000 & 0.30 \\
\hline Cancellous Bone & 690 & 0.30 \\
\hline
\end{tabular}

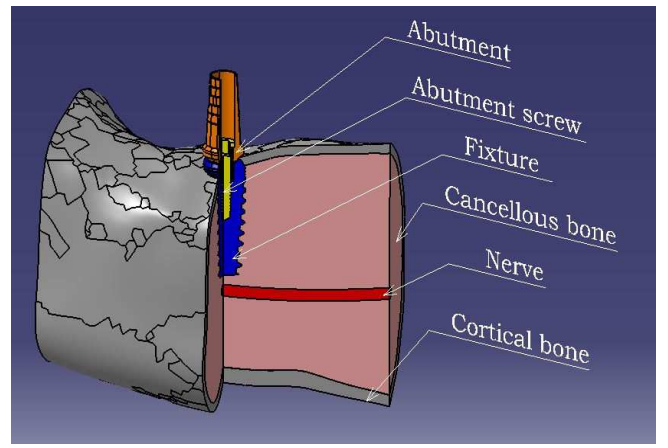

Figure 6: Cross- sectional View Shown on the STEP File of the Mandible.

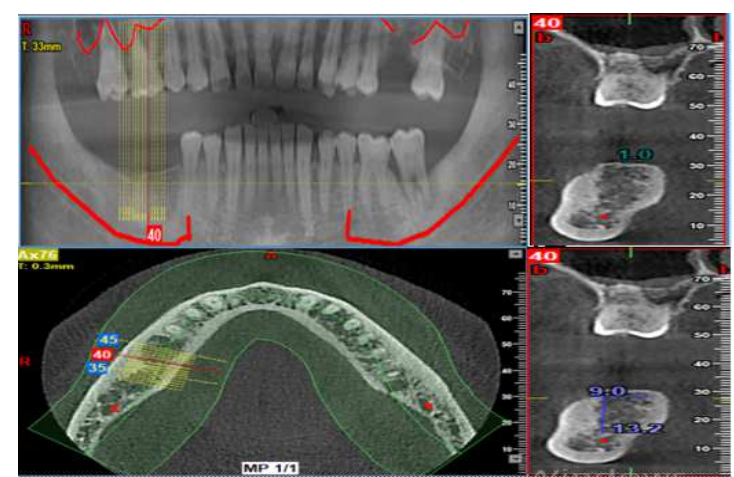

Figure 7: NNT Viewer Showing the Implant Position (left side yellow lines) and thickness of the Cortical Bone (right upper side).

\subsection{Loads and Boundary Conditions}

Static analysis is performed on the FEA model to solve the occlusal force conditions and torque applied during implant insertion. Occlusal is the force applied normal on the top face of the abutment. To analyse the effect of the implant with applied torque, the torque loads are applied on the internal hex faces around the central axis of the implant. In both the cases the boundary conditions are all Degrees of Freedom applied on the base of the cortical bone. The interfaces of the bone, implant, abutment, cortical bone and cancellous bone were considered as "Tie Contact" condition. The contact surfaces between implant systems were considered in a sliding state with friction at the interface. The Occlusal force of $24 \mathrm{~N}, 50 \mathrm{~N}$ and $76 \mathrm{~N}$ were used on the implant to perform analysis, these values are taken based on the literature work done by using optical fiber bragg gratings method which is used to determine the occlusion on the first molar location [12]. The Implant insertion torque of $30 \mathrm{Ncm}, 35 \mathrm{Ncm}, 40 \mathrm{Ncm}$ are taken based on the literature work presented on Dental Implant Insertion Torque and Bone Density- Short Review [10]. Below figures 8 and 9 shows the first molar missing on the left side and the implant insertion to be done. The person chosen for performing FEA Analysis is having D2 type of bone. 


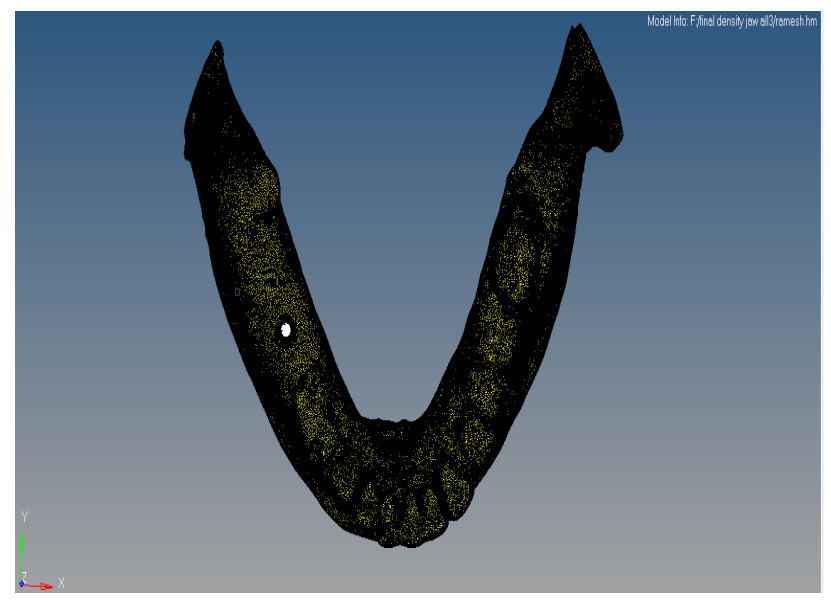

Figure 8: STL File of the Mandible Showing First Molar Missing teeth before Segmentation (left side)

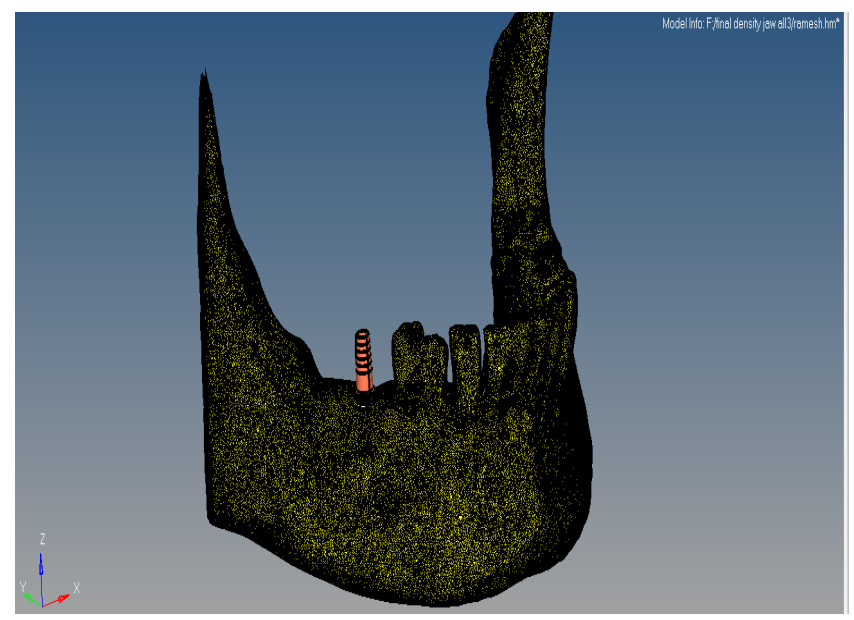

Figure 9: STL File of the mandible showing implant position and location in first molar missing teeth before Segmentation

\subsection{FEA Analysis of the Insertion Torque}

Insertion torque represents the resistance of the bone during implant placement. It is a measurement of the resistance that the system encounters during its advancement in the apical direction by means of a rotating moment on its axis. The torque values of $300 \mathrm{~N}-\mathrm{mm}, 350 \mathrm{~N}-\mathrm{mm}, 400 \mathrm{~N}-\mathrm{mm}$ is considered to solve the total deformation maximum and Vonmises stress happening on the mandible. The location of the first molar missing on the human mandible is segmented to perform the analysis. Figure 10 shows the sectional view of the mesh generated on the segmented STEP file and implant showing number of nodes and elements. 


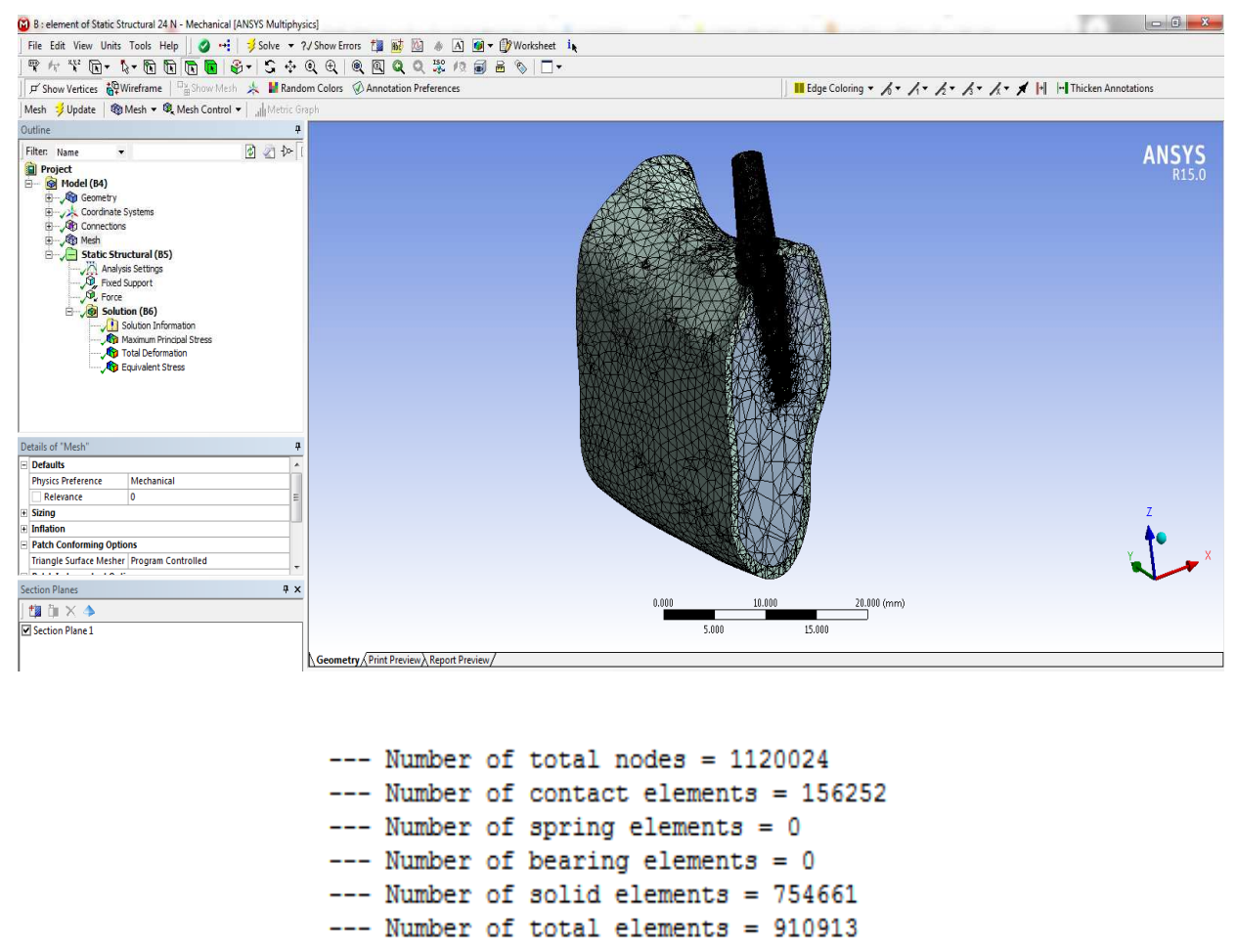

Figure 10: Mesh Generation on the Segmented STEP File of the Mandible with Implant

\subsection{Insertion of Static Structural Torque of 300 N-mm}

Below figure 11 shows the direction of the fixture rotation, and figures 12 and 13 shows the total deformation, Von-Mises Stress formed when the insertion torque of $300 \mathrm{~N}-\mathrm{mm}$ of the Implant Genesis dental implant fixture is applied on the patient's STEP File.

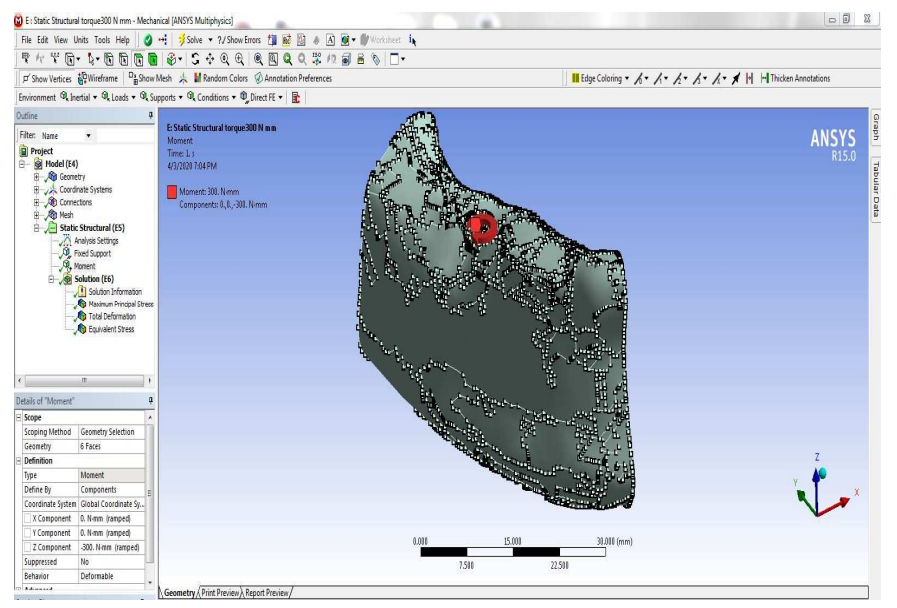

Figure 11: Implant Fixture Moment Direction on the STEP File of the Mandible. 


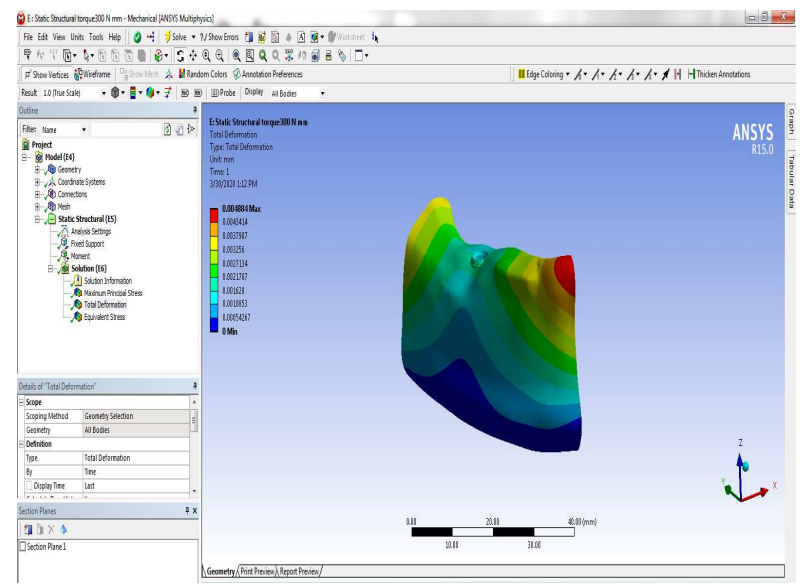

Figure 12: Total Deformation Formed on the STEP File of the Mandible.

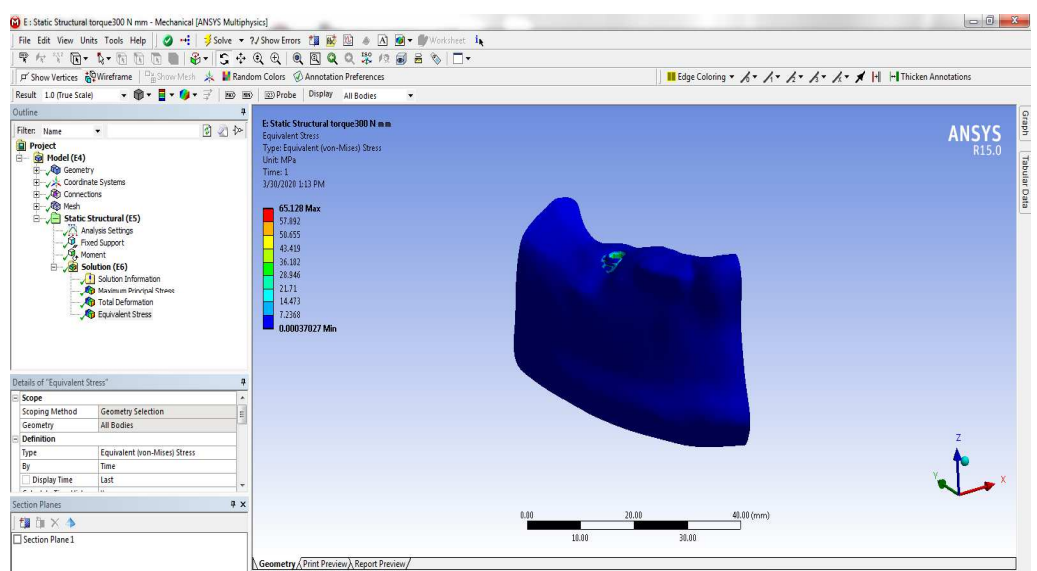

Figure 13: Von-Mises Stress Formed on the STEP File of the Mandible.

\subsection{Insertion of Static Structural Torque of 350 N-mm}

Below figures 14 and 15 shows the total deformation, Von-Mises stress formed when the insertion torque of $350 \mathrm{~N}$-mm of the Implant Genesis fixture is applied on the patient's STEP File.

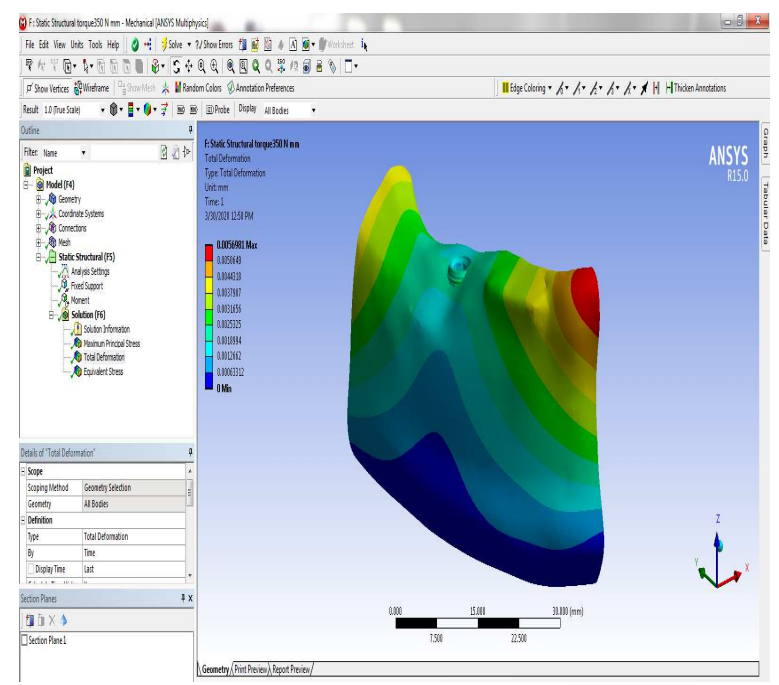

Figure 14: Total Deformation Formed on the STEP File of the Mandible. 


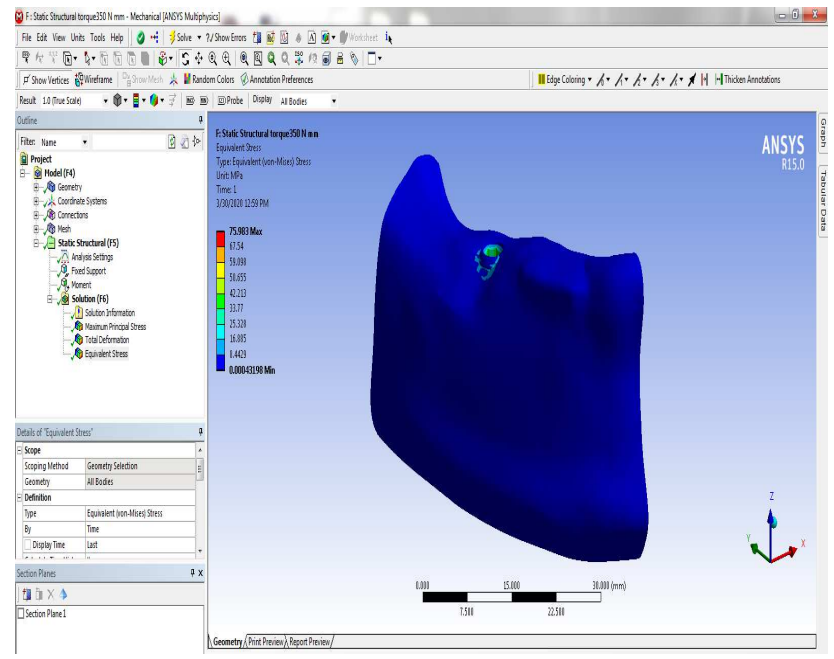

Figure 15: Von-Mises Stress Formed on the STEP File of the Mandible

\subsection{Insertion of Static Structural Torque of $400 \mathrm{~N}-\mathrm{mm}$}

Below figures 16 and 17 shows the total deformation and Von-Mises Stress formed when the insertion torque of $400 \mathrm{~N}$ $\mathrm{mm}$ of the Implant Genesis fixture is applied on the patient's STEP File.

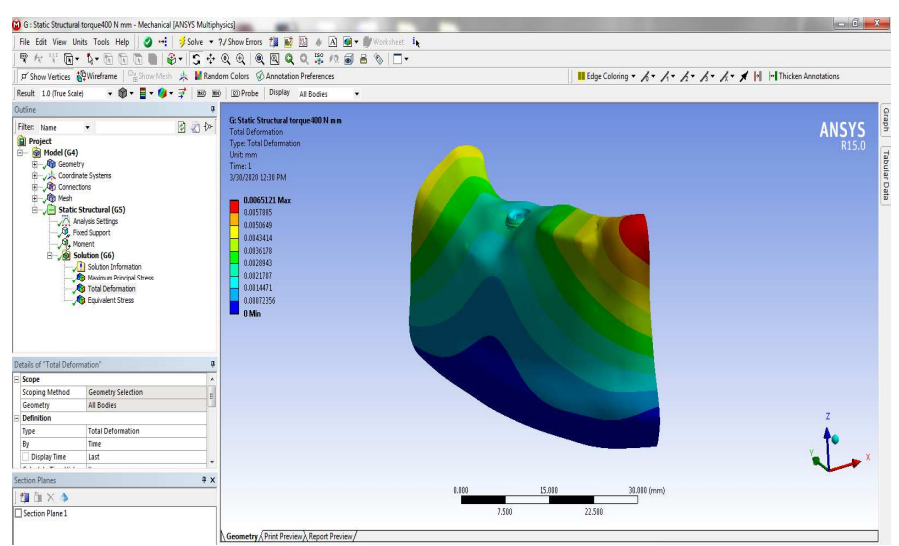

Figure 16: Total Deformation Formed on the STEP File of the Mandible.

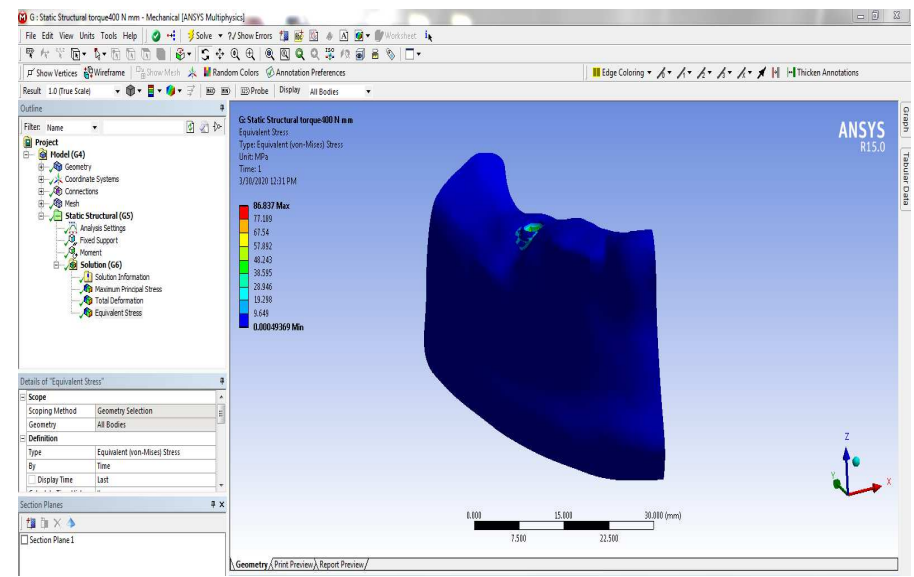

Figure 17: Von-Mises Stress Formed on the STEP File of the Mandible. 


\subsection{FEA Analysis of the Occlusal Force}

Occlusion means simply the contact between the teeth. It is the relation between the maxillary (upper) and mandibular (lower) teeth when they approach each other during chewing. The occlusal force values of $24 \mathrm{~N}, 50 \mathrm{~N}$ and $76 \mathrm{~N}$ is considered to solve the total deformation, Von-Mises Stress happening on the location of first molar missing on the mandible after implant insertion is done. After insertion of the implant $24 \mathrm{~N}$ is considered for Occlusion, $50 \mathrm{~N}$ is for biting and $76 \mathrm{~N}$ is for maximum biting as per literature.

\subsection{Occlusal Force of 24N}

The FEA is assumed to be a state of optimal osseointegration which means the cortical and cancellous bone were assumed to be perfectly bonded to the implant. Below figures 18 and 19 shows the Von-Mises Stress and Total deformation formed when the Occlusal force of $24 \mathrm{~N}$ is applied after the assembly of the Abutment, Abutment screw over the inserted fixture on the patient's STEP File.

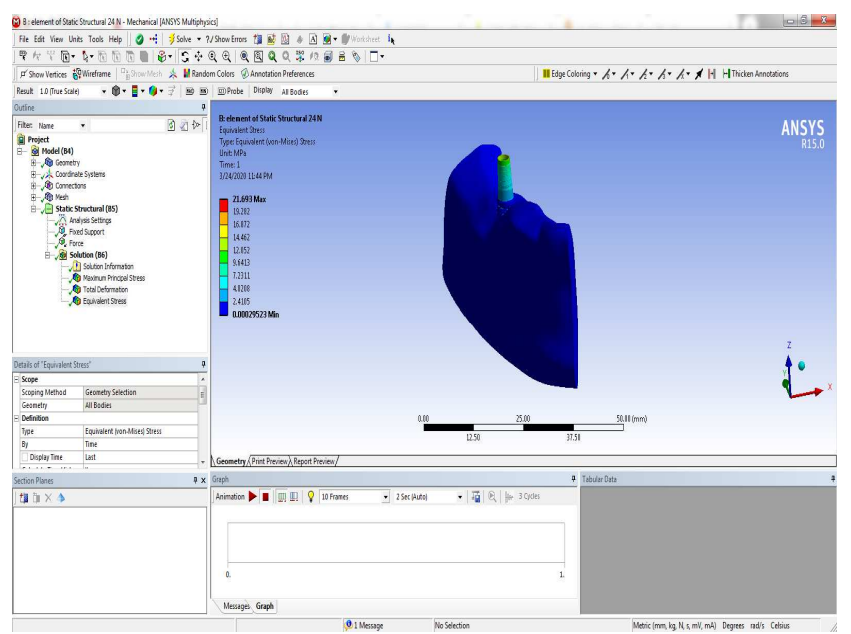

Figure 18: Von-Mises Stress Formed on the STEP File of the Mandible

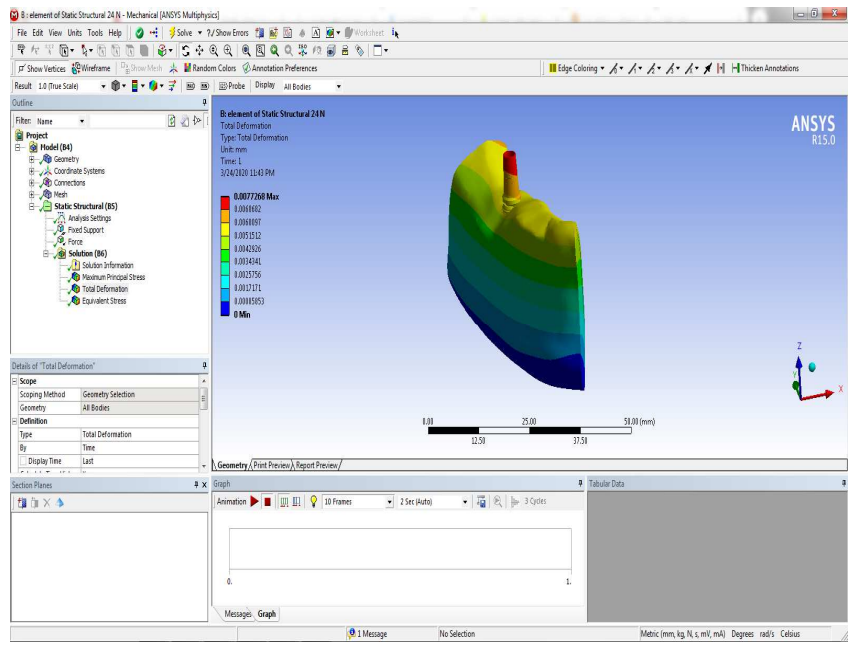

Figure 19: Total deformation Formed on the STEP File of the Mandible. 


\subsection{Occlusal Force of $50 \mathrm{~N}$}

Below figures 20 and 21 shows the total deformation, Von-Mises Stress formed when the occlusal force of $50 \mathrm{~N}$ is applied after the assembly of the Abutment, Abutment screw over the inserted fixture on the patient's STEP File.

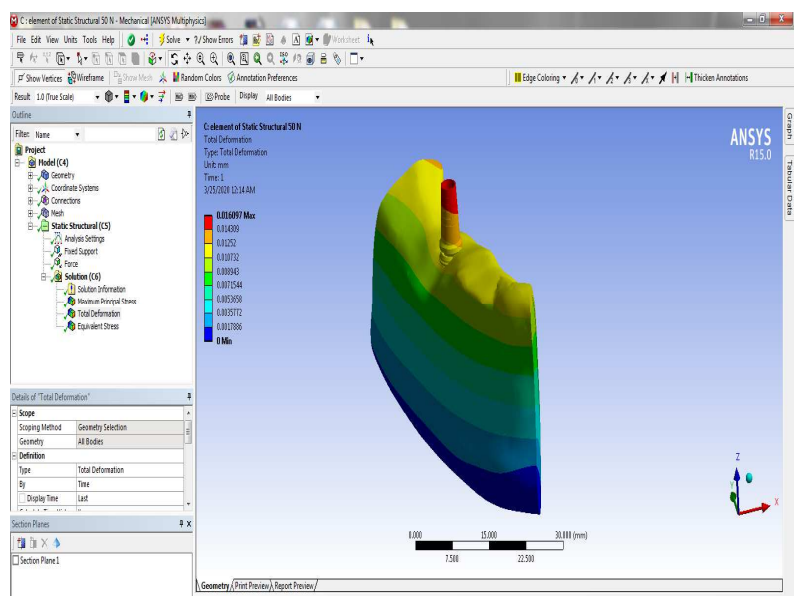

Figure 20: Total Deformation Formed on the STEP File of the Mandible.

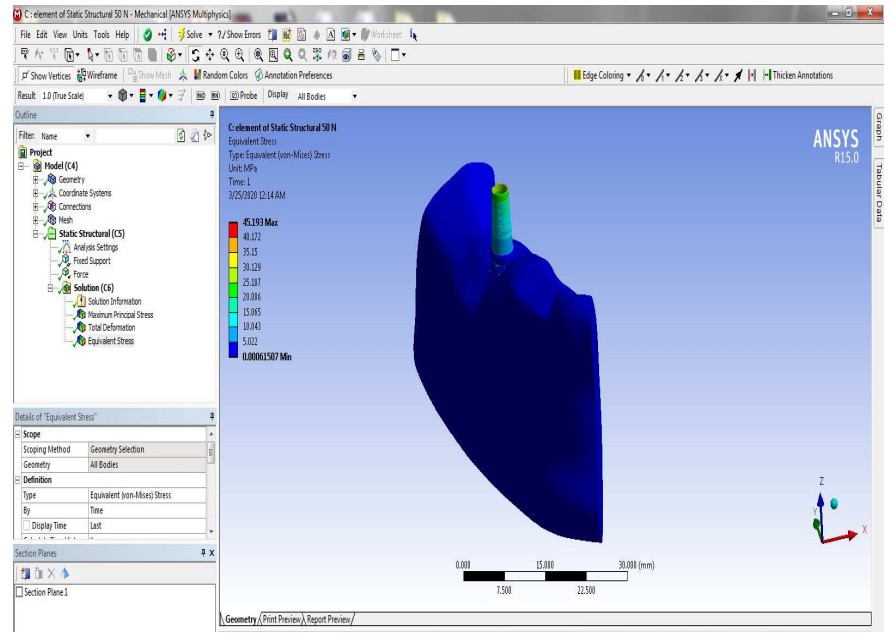

Figure 21: Von-Mises Stress Formed on the STEP File of the Mandible.

\subsection{Occlusal Force of $76 \mathrm{~N}$}

Below figures 22 and 23 shows the total deformation, Von-Mises Stress formed when the Occlusal force of $76 \mathrm{~N}$ is applied after the assembly of the Abutment, Abutment screw over the inserted fixture on the patient's STEP File. 


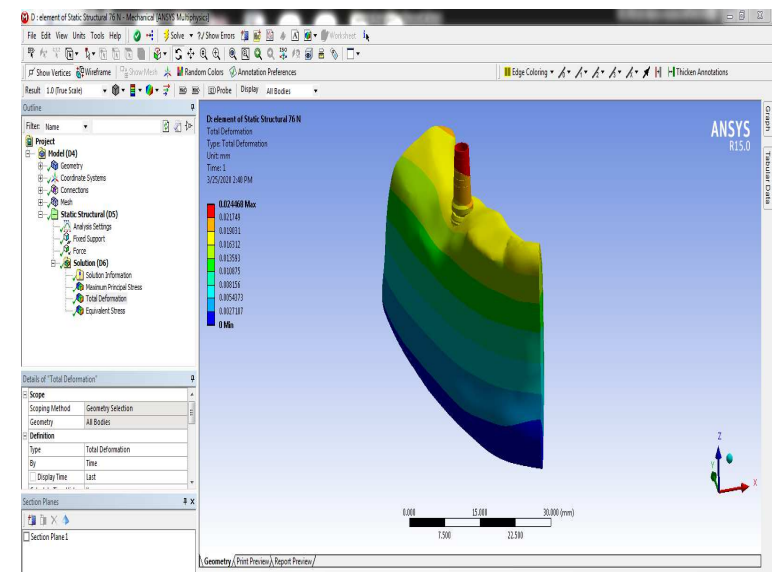

Figure 22: Total Deformation Formed on the STEP file of the Mandible.

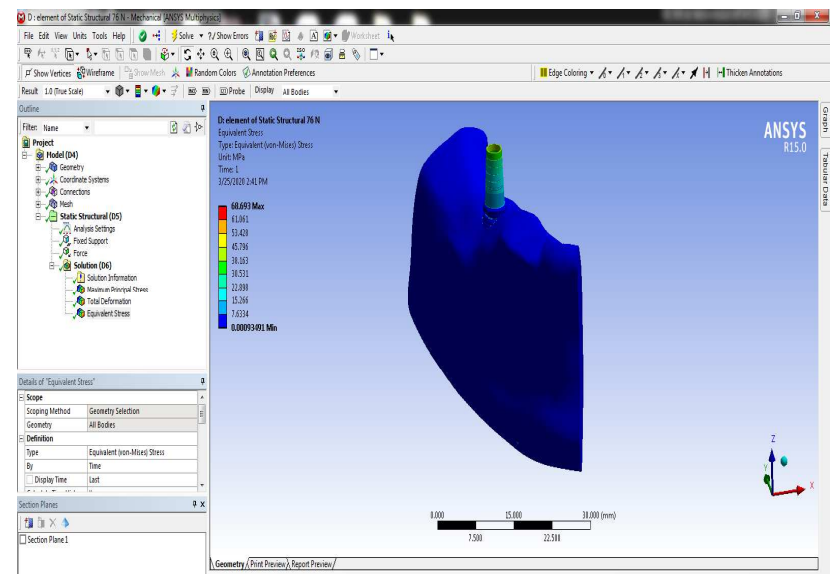

Figure 23: Von-Mises Stress formed on the STEP File of the Mandible.

\section{RESULTS AND DISCUSSIONS}

The following are the results attained after performing analysis on the STEP mandible file of the male patient, aged 53 years old for Insertion; the Torque and Occlusal force is shown at Table 4.

Table 4: Occlusal Force and Torque Results Attained

\begin{tabular}{|c|c|c|}
\hline \multicolumn{3}{|c|}{ Insertion Torque } \\
\hline Loads & Total Deformation (Max) & Vonmises Stress \\
\hline $300 \mathrm{~N}-\mathrm{mm}$ & 0.004884 & 65.128 \\
\hline $350 \mathrm{~N}-\mathrm{mm}$ & 0.0056981 & 75.983 \\
\hline $400 \mathrm{~N}-\mathrm{mm}$ & 0.0065121 & 86.837 \\
\hline \multicolumn{3}{|c|}{ Occlusal Force } \\
\hline $24 \mathrm{~N}$ & 0.0077268 & 21.693 \\
\hline $50 \mathrm{~N}$ & 0.016097 & 45.193 \\
\hline $76 \mathrm{~N}$ & 0.024468 & 68.693 \\
\hline
\end{tabular}

\section{Factor of Safety Calculation for Implant Genesis Aktiv Implant}

Table 5 shows the Mechanical Properties of Titanium and its alloys used in dental implantology [13]. These values are used for the calculation of Factor of Safety for Fixture and Abutment. Implant fixture is made of Titanium Grade 4 and Abutment is made of Grade 5. 
Table 5: Mechanical Properties of Titanium and its Alloys in Dental Implantology

\begin{tabular}{|l|c|c|c|c|c|}
\hline \multicolumn{1}{|c|}{ Properties } & Grade 1 & Grade 2 & Grade 3 & Grade 4 & Grade 5 \\
\hline Tensile Strength (Mpa) & 240 & 345 & 450 & 550 & 860 \\
\hline Yield strength (MPa) & 170 & 275 & 380 & 485 & 795 \\
\hline Elongation (\%) & 24 & 20 & 18 & 15 & 10 \\
\hline Reduction of Area (\%) & 30 & 30 & 30 & 25 & 25 \\
\hline
\end{tabular}

The material used for the Implant Genesis Aktiv Implant is made of Titanium Grade 4 and is having ductile property; hence the Factor of Safety is calculated according to the ductile material property. In ductile materials yield is measured at a point of deformation. Hence, for ductile materials FOS= Yield strength/ Maximum Stress is considered for calculation. The factor of safety is calculated for fixture and the abutment. Tables 6 and 7 shows the Factor of Safety values attained from the fixture after applying the Insertion Torque of $300 \mathrm{~N}-\mathrm{mm}, 350 \mathrm{~N}-\mathrm{mm}$ and $400 \mathrm{~N}-\mathrm{mm}$ and Occlusal force of $24 \mathrm{~N}, 50 \mathrm{~N}$ and $76 \mathrm{~N}$ after the assembly of the abutment to the fixture on the mandible which completes the Implantation Procedure. For grade 4, Yield Strength is taken as 485Mpa for fixture and grade 5 it is $795 \mathrm{Mpa}$ for abutment to calculate the Factor of Safety.

Table 6: Factor of Safety values Attained for Insertion Torque

\begin{tabular}{|c|c|}
\hline Factor of Safety Values Attained for the Fixture (Ti Grade 4) \\
\hline Loads (N) & FOS Values \\
\hline $300 \mathrm{~N}-\mathrm{mm}$ & 7.446 \\
\hline $350 \mathrm{~N}-\mathrm{mm}$ & 6.3 \\
\hline $400 \mathrm{~N}-\mathrm{mm}$ & 5.585 \\
\hline
\end{tabular}

Table 7: Factor of Safety values attained for Occlusal Force

\begin{tabular}{|c|c|c|}
\hline \multicolumn{3}{|c|}{ Factor of Safety Values Attained after assembly of the abutment to the Fixture } \\
\hline Loads (N) & Implant Fixture (Ti Grade 4) & Abutment (Ti Grade 5) \\
\hline $24 \mathrm{~N}$ & 22.357 & 36.64 \\
\hline $50 \mathrm{~N}$ & 10.731 & 17.30 \\
\hline $76 \mathrm{~N}$ & 7.06 & 11.573 \\
\hline
\end{tabular}

\section{CONCLUSIONS}

The factor of safety values attained for the implant fixture is 7, 6 and 5 for the insertion torque of $300 \mathrm{~N}-\mathrm{mm}$, 350N-mm and $400 \mathrm{~N}-\mathrm{mm}$. Similarly, the factor of safety values attained for the occlusal force of $24 \mathrm{~N}, 50 \mathrm{~N}$ and $76 \mathrm{~N}$ are 22,10 and 7 for the fixture and 36, 17 and 11 for the Abutment. Hence, the results obtained are under Factor of Safety. All the stresses generated are permissible to the mandible. The pre-processing parameters, which are considered to choose the type of implant suitable for the patient and the bone density from the NNT Viewer by New Tom has provided the necessary inputs for performing analysis. So the results are under Factor of Safety, which proves that the Implant Genesis Aktiv Models are made under safe design. So, Implant Genesis Aktiv Dental implant of diameter 5mm and Length $11.5 \mathrm{~mm}$ is suitable for implanting in the first molar area for the selected male patient, aged 53 years and the stress values generated are permissible and found to be safe after the implantation. 


\section{ACKNOWLEDGEMENT}

The authors sincerely thank Implant Genesis Kerala, Dr. Arvind's Dental and Maxillofacial Clinic and Dr. Arvind UD, Oral and Maxillofacial Surgeon, Hyderabad for generously helping us while modelling the Implants, sharing complete details pertaining to Implants and and also for giving valuable inputs throughout the work. The authors express special thanks to Mr. T. Malyadri, Assistant Professor and Sayina Koteswari PG Scholar of M.Tech (CAD/CAM), Department of Mechanical Engineering, VNR VJIET, Hyderabad for extending their continuous support throughout the work.

\section{REFERENCES}

1. Sun J., Jiao T., Tie Y., Wang D.M. “Three dimensional finite element analysis of the application of attachment for obturator framework in unilateral maxillary defect”, Journal of Oral Rehabilitation; 35 (2008): 695-699.

2. Gao J., Xu W., Ding Z "3D finite element mesh generation of complicated tooth model based on CT slices", Computer Methods and Programs in Biomedicine ;28 (2006) Elsevier:916-924.

3. Viceconti M., Zannoni C., Testi D. "The Multimode application framework: A rapid application development tool for computer aided medicine”, Computer Methods Programs in Biomedicine; 85 (2007) Elsevier: 138-151.

4. Lu S., Li T., Zhang Y. "Biomechanical optimization of the diameter of distraction screw in distraction implant by threedimensional finite element analysis”, Computers in Biology and Medicine ; 43 (2013) Elsevier:1949-1954.

5. Pessoa R.S., Muraru L., Junior E.M. "Influence of implant connection type on the biomechanical environment of immediately placed implants-CT-based nonlinear, three-dimensional finite element analysis”, Clinical Implant Dentistry and Related Research; 12 (2010): 219-234.

6. Shigemitsu R., Yoda N., Ogawa T. "Biological-data-based finite-element stress analysis of mandibular bone with implant supported overdenture”, Computers in Biology and Medicine; 54 (2014) Elsevier: 44-52.

7. Berglundh T., et al. "A systematic review of the incidence of biological and technical complications in implant dentistry reported in prospective longitudinal studies of at least 5 years". Journal of Clinical Periodontology; 29.3 (2002): 197-212.

8. Rocha S., et al. "Effect of platform switching on crestal bone levels around implants in the posterior mandible: 3 years results from a multicentre randomized clinical trial”. Journal of Clinical Periodontology; 43.4 (2016): 374-382.

9. Gaviria L., et al. "Current trends in dental implants". Journal of the Korean Association of Oral and Maxillofacial Surgeons 40.2 (2014): 50-60.

10. C.J.Venkatakrishnan., et al. "Dental Implant Insertion Torque and Bone Density - Short Review". Biomedical and Pharmacology Journal, Vol. 10 (3) (2017):1305- 1309.

11. Won Hyeon Kim., et al. "Optimized Dental Implant Fixture Design for the Desirable Stress Distribution in the Surrounding Bone Region: A Biomechanical Analysis”. Materials 12 MPDI, Basel, Switzerland; 17 (2019): 1-17.

12. Ilda Abe., et al. "The force magnitude of a human bite measured at the molar intercuspidation using fiber Bragg gratings. Journal of Microwaves, Optoelectronics and Electromagnetic Applications, Vol. 16; 2 (2017): 434-444.

13. Roland Masa and Gabor Braunitzer "Titanium and its Alloys in dental implantology”. Research Article on Implants, (2017): 06-10. 


\section{AUTHOR'S PROFILE}

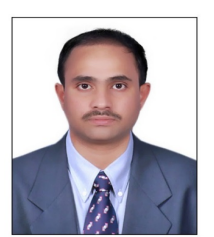

Mr. Kode Jaya Prakash currently working as Assistant Professor in Mechanical Engineering Department at VNR Vignana Jyothi Institue of Engineering \& Technology, Hyderabad, since 2010. Also Pursuing External PhD Under the guidance of Dr. Balla Srinivasa Prasad, Associate Professor in Department of Mechanical Engineering at Gitam Institute of Technology, GITAM (Deemed to be University), Visakhapatnam. He completed B.Tech Mechanical Engineering in 2007, M.Tech (Advanced Manufacturing Systems) in 2009, from JNTUH. His area of interest lies in "Additive Manufacturing”. He published 9 International Journals, presented 4 International and 3 National Conferences till date.

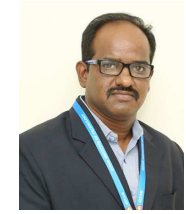

Dr. Balla Srinivasa Prasad is presently working as Associate Professor in Department of Mechanical Engineering, Gitam Institute of Technology, GITAM (Deemed to be University), Visakhapatnam since 2003. He was graduated in B.E (Mechanical Engineering) from Andhra University- Visakhapatnam and Master's Degree in Production Engineering from S.V.University, Tirupathi. He was awarded Ph.D from Andhra University in 2010. He has published 31 papers in peer reviewed journals with 212 Citations and Published 05 books in the area of Manufacturing and actively engaged in research fields of Additive Manufacturing, Tool Condition Monitoring, Multi Sensor Fusion and 3D Surface Topology. He has more than 16 years of teaching experience at both PG and UG level students. At present 08 Research Scholars are working in his guidance for their PhD Degree.

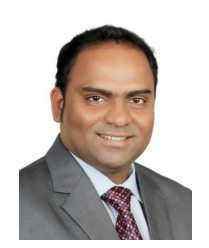

Dr. Arvind UD, Oral \& Maxillofacial Surgeon is graduated from SVS Institute of Dental Sciences, 2007 and Post Graduated from Panineeya Mahavidyalaya Institute of Dental Sciences in Oral \& Maxillofacial Surgery, 2012. Currently he is CEO of Dr. Arvind's Dental \& Maxillofacial Clinic, Hyderabad. He is a Reader at Department of OMFS, HKE. S.Nijalingappa Institute of Dental Sciences, Gulbarga. Also working as a Faculty in International Board of Oral Implantology (IBOI), USA. He received "Excellence in Dental Implantology" award by Indian Health Professional Awards, New Delhi, 2017. Currently he is an EC Member for AOMSI Telangana State Chapter from 2015 to till date and also General Secretary for Telangana State Dental Surgeons Forum from 2014 to till date. He has Published 04 International and 06 National journals. 